\title{
MODELLING EVENTS: THE SHORT-TERM ECONOMIC IMPACT OF LEAVING THE EU
}

Jessica Baker, Oriol Carreras, Simon

Kirby, Jack Meaning and Rebecca

Piggott

NIESR Discussion Paper No. 461

Date: $20^{\text {th }}$ June 2016 


\section{About the National Institute of Economic and Social Research}

The National Institute of Economic and Social Research is Britain's longest established independent research institute, founded in 1938. The vision of our founders was to carry out research to improve understanding of the economic and social forces that affect people's lives, and the ways in which policy can bring about change. Seventy-five years later, this remains central to NIESR's ethos. We continue to apply our expertise in both quantitative and qualitative methods and our understanding of economic and social issues to current debates and to influence policy. The Institute is independent of all party political interests.

National Institute of Economic and Social Research

2 Dean Trench St

London SW1P 3HE

T: +44 (0)20 72227665

E: enquiries@niesr.ac.uk

niesr.ac.uk

Registered charity no. 306083

This paper was first published in June 2016

(c) National Institute of Economic and Social Research 2016 


\title{
Modelling events: the short-term economic impact of leaving the
} EU

\author{
Jessica Baker, Oriol Carreras, Simon Kirby, Jack Meaning and Rebecca \\ Piggott
}

\section{Abstract}

This paper presents a framework for modelling important socio-economic events in order to provide an informative counterfactual. This involves mapping the deep underlying shock associated with the event itself into a series of more tractable shocks consistent with the model being applied and calibrated from data, existing literature or ancillary analysis. The results should then be subject to testing of their sensitivity to the assumptions made. As a practical example, the paper uses the National Institute's Global Econometric Model (NiGEM) to consider the short-term economic impact to the UK of leaving the European Union. We find that the UK economy would be around $2 \frac{1}{2}$ per cent smaller 2 years after a decision to leave the EU when compared to the counterfactual of deciding to remain a member.

\section{Acknowledgements}

The authors would like to thank Jagjit Chadha, James Warren and Monique Ebell as well as an unknown referee for helpful comments.

A version of this paper is forthcoming in Economic Modelling.

This research did not receive any specific grant from funding agencies in the public, commercial, or not-for-profit sectors

\section{Contact details}

Corresponding author: Rebecca Piggott, (r.piggott@niesr.ac.uk), National Institute of Economic and Social Research, 2 Dean Trench Street, London SW1P 3HE

Keywords: Macroeconomic modelling; Uncertainty; Risk premia; Investment

JEL classification codes: D80, E17, E27 and E65 


\section{Introduction}

Counterfactual paths for the economy, or forecasts conditional on a specific deviation, are a common feature of economic modelling. They can inform about the likely impact of a policy change, such as a decision by the monetary authority to raise interest rates, or of shocks such as an unanticipated drop in the global oil price.

The same analytical techniques used in the creation of such counterfactuals can also be applied to understanding the potential outcomes of more complex, large-scale socio-economic events. These events can be characterised as forks in the road travelled by the economy whereby the event itself determines which path prevails.

At the time of writing the impending referendum on the United Kingdom's continued membership of the European Union (EU) is one such event. As with many of these significant socio-economic events, the fact that the event will occur is foreseeable and anticipated, even though the precise outcome is not. In the case of the EU referendum, the date of the vote, $23^{\text {rd }}$ June 2016 , was officially announced 4 months earlier in February 2016, with a vaguer commitment that it would take place in the near future signalled even earlier. It also represents a relatively clear-cut fork in the economy's trajectory with the option to maintain the status quo or transition to a new regime, and the choice over which of these futures occurs decided at a fixed point in time. Whilst prior to the event either outcome may prevail, reflected by the highly bi-modal nature of the probability distribution, once the event has occurred, in this case the vote itself, the distribution of outcomes will be narrowed to only those associated with that outcome. That is not to say that there will not exist a distribution of outcomes associated with each path, or even conceivably some overlap in the distributions around each. For instance, a narrow margin on the vote, either way, may lead to a very different outcome compared with a world in which the result is decisively in favour of one campaign or the other. However, despite this, the question facing voters in the referendum is binary, and so this presents a useful basis for deriving a counterfactual.

Such an event allows for a specific type of modelling exercise to be undertaken. It becomes possible to think about the two distinct possible states of the world separately and thus contrast the impact of taking one path compared to the other. In essence the bi-modal view of the future is disaggregated to the two separate modes, each conditioned on the outcome of the event being one way or the other.

The main contribution of this paper is two-fold. First, as a general point it seeks to provide a blueprint for undertaking an exercise of the nature described above. Second, it provides a practical exposition of the proposed method by means of a contemporary example, the UK's referendum on membership of the EU. In doing so it provides both a qualitative and quantitative assessment of the likely impact for the UK economy of a decision to leave the EU.

In a similar piece of work using NiGEM's predecessor, NiDEM, Pain and Young (2004) also analyse the effects of leaving the EU on the UK economy. They conclude that living standards would be adversely affected, mostly due to a decline in technical efficiency resulting from lower future levels of inward FDI. Our analysis differs from theirs in that we are primarily concerned with the short-run effects of a decision to leave the EU and we additionally include the effects of heightened uncertainty and associated increases in risk premia as trade deal negotiations take place.

To that end, the remainder of the paper is structured as follows; section 2 details the proposed framework for studying a socio-economic event of the type described. Section 3 provides a general 
overview of the model used in the applied work, which follows in sections 4-7. Section 8 then describes the particular results of our work on the European Union before the paper concludes.

\section{Modelling a large socio-economic event}

The referendum on the UK's membership of the European Union represents a large and complex shock that will transmit through the economy via a myriad of channels. Other such examples might be a switch to an independent central bank, see for example Chadha et al (2007) who analyse the effects of the surprise decision by the UK government to grant operational independence to the Bank of England, or German unification, see Hallett et al (1996).

Most, if not all economic models are ill-equipped for the introduction of a deep shock of this nature in its most primitive form. Rather, the first stage of any analysis of such an event must be a mapping exercise, decomposing the underlying disturbance into a constellation of more tractable shocks based on the likely channel of transmission and that, when applied in conjunction with one another, serve as a reasonable proxy for the single primitive innovation.

It is then necessary to provide plausible calibrations for each of these chosen shocks. This can be done by analysing historic data, drawing on the existing evidence base, or through more in-depth ancillary analysis such as impulse response matching, or more generally, using output from one model to inform the inputs for another. It is this 'inputs' stage that can introduce variation in eventual outcomes, even among economists that agree on the broad qualitative narrative and even among those that use the same modelling framework for their analysis.

Having established the set of shocks that drive the analysis and their calibrations it is enlightening to evaluate each in turn. This allows the clear exposition of the various transmission mechanisms at play, and also enables relative comparisons across these channels. For instance, in a scenario of increased risk that manifests as a shock to the exchange rate and a tightening of domestic credit conditions; how much does the impact on demand from a shock to the exchange rate offset the impact from a tightening of domestic credit conditions?

These shocks must then be brought together in a consistent manner. Of crucial importance is the timeline of the socio-economic event in question. Thought must be given to the sequencing of shocks and when exactly the new information contained within the shock enters the decisionmaking process of agents within the model. This is especially important when operating with forward-looking agents and financial markets, as we do in the exercise that follows. The shock may occur at time $t$, but if it is anticipated, it may feature either fully or partially, in agents' expectations at time t-1 or earlier. Conversely, if agents are forward-looking but do not anticipate the shock, then any forward-looking variables cannot reflect the shock in their information set until the moment it is introduced, or else agents will pre-emptively change their behaviour, generating an inconsistency in the exercise.

Once all of this is done, and if possible at each stage along the way, sensitivity analysis should be undertaken to gauge how robust the result is to varying assumptions and the choice of shock size, combination and timing. Other important sensitivity analysis for exercises on shocks like these focus on the policy response. Variation in policy reaction functions can be both a way to ensure robustness, but also of interest in and of itself when policy makers are searching for guidance on how to respond to a large socio-economic event.

In summary, our proposed framework for modelling a large socio-economic event is: 
1. Decompose the underlying event into a collection of more tractable shocks consistent with the model to be utilised for the analysis

2. Calibrate these individual shocks

3. Analyse each shock in isolation to uncover transmission mechanisms

4. Combine the shocks in a manner consistent with the event timeline and expectation formations

5. At all stages, carry out sensitivity analysis to differing calibrations, expectations and policy specifications

This paper will now consist of an exposition of the process outlined above through the lens of the United Kingdom's referendum on membership of the European Union, held on $23^{\text {rd }}$ June 2016.

\section{The NiGEM model}

This section provides a succinct non-technical exposition of the National Institute's Global Econometric model, NiGEM. Where relevant to the analysis, details of the model will be presented in the text to follow, but an in-depth discussion falls beyond the scope of this paper. ${ }^{1}$

NiGEM is a global econometric model, and most countries in the $\mathrm{EU}^{2}$ and the $\mathrm{OECD}^{3}$ as well as major emerging markets are modelled individually. The rest of the world is modelled through a set of regional blocks so that the model is global in scope. All country models contain the determinants of domestic demand, export and import volumes, prices, current accounts and gross foreign assets and liabilities. Output is tied down in the long run by factor inputs and technical progress interacting through production functions. Economies are linked through trade, competitiveness and financial markets and are fully simultaneous.

Agents are presumed to be forward-looking, at least in some markets, but nominal rigidities slow the process of adjustment to external shocks. The model has complete demand and supply sides and there is an extensive monetary and financial sector, together with household and government sectors. As far as possible the same theoretical structure has been adopted for each country. As a result, variations in the properties of each country model reflect genuine differences emerging from estimation, rather than different theoretical approaches.

Policy reactions are important in the determination of speeds of adjustment. Nominal short-term interest rates are set in relation to a forward looking feedback rule. Long-term interest rates are the forward convolution of future short-term interest rates with an exogenous term premium. An endogenous tax rule ensures that governments remain solvent in the long run; the deficit and debt stock return to sustainable levels after any shock, as is discussed in Chen (2014). Exchange rates are forward looking and so can 'jump' in response to a shock.

Within NiGEM, labour markets in each country are described by a wage equation (see Barrell and Dury, 2003 for a detailed description) and a labour demand equation (see, for example, Barrell and Pain, 1997). The wage equations depend on productivity and unemployment, and have a degree of rational expectations embedded in them - that is to say the wage bargain is assumed to depend partly on expected future inflation and partly on current inflation. The speed of the wage adjustment is estimated for each country. Wages adjust to bring labour demand in line with labour supply.

\footnotetext{
${ }^{1}$ For further details, the reader is referred to the separate appendix which accompanies this paper and the NiGEM website: https://nimodel.niesr.ac.uk/.

${ }^{2}$ With the exception of Cyprus, Luxembourg and Malta.

${ }^{3}$ With the exception of Chile, Iceland and Israel.
} 
Employment depends on real producer wages, output and trend productivity, again with speeds of adjustment of employment estimated and varying for each country.

\section{Decomposing leaving the EU into tractable shocks}

A large socio-economic event can often be thought of in terms of regimes. The outcome of the event determines which regime prevails in the future and thus analysis of the event seeks to describe the impact of moving from the current regime to a new one. Part of this is determined by the long-run characteristics of the new regime, but there is also likely to be some immediate consequences and more short-run shocks as we transition from the old regime to the new. We discuss briefly the modelling of the long-run effects of structural changes associated with a decision to leave the EU in Section 7 alongside a description of how we combine the short and long-run elements in a consistent manner. ${ }^{4}$ However, in this section we focus on the set of shocks capturing the short-term developments, which can be grouped into three broad areas: financial market developments, delays in corporate investment plans and expectational effects arising from long-run structural changes. Each of these areas draws on an established evidence base concerning a plausible way in which the underlying shock may manifest itself.

\section{Financial markets}

Financial markets are bound to respond to the change in regime that a vote to leave implies. First, sterling is likely to depreciate as the uncertainty surrounding the outcome of the trade deal negotiations will decrease investor's appetite for UK assets. In the first 4 months of 2016, sterling depreciated by around 8 per cent against a basket of currencies when measured on a tradeweighted basis. Analysis of option-implied sterling volatility and correlations with referendumrelated series, such as betting market odds or days in which news on the referendum are released to markets suggest that a large part of this depreciation emanates from an increased risk being attached to sterling as a direct result of the referendum, see for instance Bank of England (2016) and Baker et al (2016).

Second, the cost of financing for the government is likely to increase as well, as the uncertainty triggered by a vote to leave dissuades investors from holding gilts. Around $1 / 4$ of the outstanding gilt market is held by overseas investors who are easily able to move their money across international markets, and who might be particularly sensitive to the exchange rate movements and uncertainty associated with a vote to leave. What is more, if investors believe that leaving the EU will have negative consequences for the medium and long-term outlook for the UK economy, they may be inclined to lessen the weighting on UK assets in their portfolio. Such a change in sentiment may cause a sell-off in gilts, or at least a fall in demand, which for a given supply would lower the price. On top of this, a number of rating agencies have intimated that a vote to leave could cause them to re-evaluate the status of UK government securities, and perhaps even prompt a downgrade, which would almost certainly result in an increase in the cost of borrowing for the UK government ${ }^{5}$.

Third, firms and households are also likely to experience higher cost of funds. The fundamental factor that determines the cost of capital, namely, the expected stream of future dividends that companies produce, will become much more difficult to forecast accurately given the uncertainty surrounding a vote to leave. As a result, the cost of capital, both in debt and equity form, should adjust to reflect this.

\footnotetext{
${ }^{4}$ A more comprehensive description of the long-run analysis of the EU referendum which underpins the discussion here can be found in Ebell and Warren (2016)

${ }^{5}$ Source: Bloomberg (2016), Moody's (2015) and Fitch Ratings (2015).
} 
Such a rise, may be amplified by the sovereign downgrade; a point made by Davies and Panetta (2011). Banks suffer from sovereign downgrading as it inflicts losses on their sovereign portfolios, reduces the value of a significant part of the assets that they can use as collateral and lessens the funding benefits that banks derive from government guarantees. As banks' balance sheets come under pressure, the cost of bank lending to firms and households is likely to increase.

\section{Corporate investment plans}

A large body of literature has looked into the effects of uncertainty on investment decisions of firms. An early strand of the literature captured in the work by Oi (1961), Hartman (1972) and Abel (1983) suggested that, contrary to common belief, uncertainty could lead to higher investment if marginal returns to investment were convex. Later on, Bernanke (1983), Pindyck (1988) and Dixit (1989) showed that under the presence of sunk costs to investment, which render marginal returns to capital concave, a firm will delay investment projects following an increase in uncertainty as there will be a value in waiting. Investing triggers a cost that cannot be recovered and therefore it is optimal for the firm to wait until the realisation of the uncertain outcome ensures sufficiently high expected returns. Leahy and Whited (1996), using firm-level data, found empirical evidence of uncertainty exerting a negative influence on investment, thus giving support to the latter strand of work. Recent work includes Bloom (2009), who finds that higher uncertainty causes firms to delay investment and hiring as well as declines in productivity growth as the rate of reallocation of resources from low to high productivity firms is inhibited. Bloom et al. (2014), who find similar results within the context of a DSGE model extended to include uncertainty shocks, and FérnandezVillaverde et al. (2015), who find that volatility in fiscal shocks also induces negative effects on economic activity within a New Keynesian model framework. There seems to be a consensus that uncertainty drives firms to delay their investment plans.

Besides theoretical work, there has been a considerable amount of empirical work to establish a link between uncertainty and economic activity. The results have been broadly in line with the lessons we learned from the theory. Beaulieu et al. (2005) analysed four major events between 1990 and 1996, including the second referendum on the question of Quebec's independence from Canada in 1995 , and found that firms with higher exposure to political risk had to generate a higher return in the period of heightened uncertainty in the run-up to the referendum. Durnev (2010) found that corporate investment becomes less responsive to stock market prices in periods surrounding elections, with the effect being largest when election results are less certain. The decline in investment-to-price sensitivity seems to be explained by market participants perceiving stock prices to be less informative during election times. Julio and Yook (2012), using data on national elections for a large number of countries between 1980 and 2005, found that firms reduce, on average, investment expenditures by 4.8 per cent during election years relative to non-election years.

\section{Expectational effects}

By the design of our exercise, all of the shocks detailed above dissipate gradually over the two-year period for negotiating a withdrawal; agents, domestically and abroad, become increasingly aware of the likely outcome at the end of this period and thus the nature of the new regime. Given the complex political and legal considerations associated with any attempt to extricate the UK from the $\mathrm{EU}$ it may be that this process proves to be more protracted in practice. Therefore our assumption that uncertainty is resolved within the two-year window can be considered relatively cautious.

Importantly, the forward looking nature of agents in NiGEM means agents will re-optimise and adjust their economic decisions long before the trade negotiations finalise, thus adding an additional 
layer of dynamics to the short-term consequences of a vote to leave. This channel will be discussed in more detail in Section 7.

\section{Calibration}

In this section we discuss the methods used to calibrate the shocks described in the previous section. We have drawn from several sources including historical data, the existing academic literature and more involved ancillary analysis. Table 1 provides a summary of all the shocks and their calibration. The interested reader looking for further details is referred to Baker et al. (2016).

Table 1. Summary of short-term shocks introduced from 2016Q3

\begin{tabular}{|c|c|c|c|}
\hline & Calibrated from & $\begin{array}{l}\text { Size of } \\
\text { shock }\end{array}$ & Duration \\
\hline$\overline{\text { Exchange rate premium }}$ & $\begin{array}{l}\text { 3-month options- } \\
\text { implied sterling } \\
\text { volatility }\end{array}$ & $\begin{array}{l}2 / 3 \text { of the } \\
\text { magnitude } \\
\text { observed in } \\
2008\end{array}$ & $\begin{array}{l}\text { Shock decays to zero over } \\
\text { the following } 7 \text { quarters }\end{array}$ \\
\hline Uncertainty & $\begin{array}{l}\text { Betting markets } \\
\text { and historical data }\end{array}$ & $\begin{array}{l}\text { Three times } \\
\text { the level in } \\
\text { 2016Q2 }\end{array}$ & $\begin{array}{l}\text { Shock decays to zero over } \\
\text { the following } 13 \text { quarters }\end{array}$ \\
\hline Term premium & $\begin{array}{l}\text { Joyce et al (2011), } \\
\text { Breedon et al } \\
\text { (2012),Meaning } \\
\text { and Warren (2015) }\end{array}$ & $\begin{array}{l}100 \text { basis } \\
\text { points }\end{array}$ & $\begin{array}{l}\text { Shock persists for } 4 \\
\text { quarters and then decays } \\
\text { to zero over the following } 4 \\
\text { quarters }\end{array}$ \\
\hline $\begin{array}{l}\text { Household and corporate } \\
\text { credit premium }\end{array}$ & $\begin{array}{l}\text { Cantor and } \\
\text { Packer (1996), } \\
\text { Alfonso et al. } \\
\text { (2012), Kiff et al. } \\
\text { (2012), historical } \\
\text { data and author's } \\
\text { calculations }\end{array}$ & $\begin{array}{l}50 \text { basis } \\
\text { points }\end{array}$ & $\begin{array}{l}\text { Shock persists for } 6 \\
\text { quarters and then decays } \\
\text { to zero over the following } \\
\text { two quarters }\end{array}$ \\
\hline Equity premium & $\begin{array}{l}\text { Historical data } \\
\text { and author's } \\
\text { calculations }\end{array}$ & $\begin{array}{l}50 \text { basis } \\
\text { points }\end{array}$ & $\begin{array}{l}\text { Shock persists for } 6 \\
\text { quarters and then decays } \\
\text { to zero over the following } \\
\text { two quarters }\end{array}$ \\
\hline
\end{tabular}

\section{Data}

Current and historical data has aided us in calibrating almost all of the shocks that we have included in our analysis. It has either provided the main source of information to calibrate a shock or has served as a means to test whether a particular calibration falls within reasonable historical boundaries.

One example to illustrate the use of market data is provided in our calibration of the shock on sterling. Exchange rates in NiGEM are defined as a forward looking risk adjusted uncovered interest rate parity condition relative to the US dollar.

$$
E\left[\frac{r x_{t+1}}{r x_{t}}\right]=\left[\frac{1+\text { int }_{t}}{1+\mathrm{usint}_{t}}\right] *\left(1+R P_{t}\right)
$$

where $t$ refers to the time period, $r x$ to the nominal exchange rate (sterling per US dollar), int to the 
domestic policy rate, usint to the policy rate in the US and RP to the risk premium. Our shock will be applied to the residual term, which we define as the risk premium.

To calibrate the shock, we looked at the options-implied 3-month sterling volatility. This series rose sharply on the day that the 3-month contract first encompassed the date of the referendum. To put this increase in context we look to recent history and see that it approximately two-thirds of the size of the spike observed in the 2008 financial crisis, figure 1. We therefore calibrated a shock to the exchange rate risk premium in the third quarter of 2016 by scaling the change in the risk premium in the fourth quarter of 2008 by two-thirds. We subsequently let the shock decay gradually until it vanishes by the end of 2017 .

Figure 1. Option implied 3-month sterling volatility

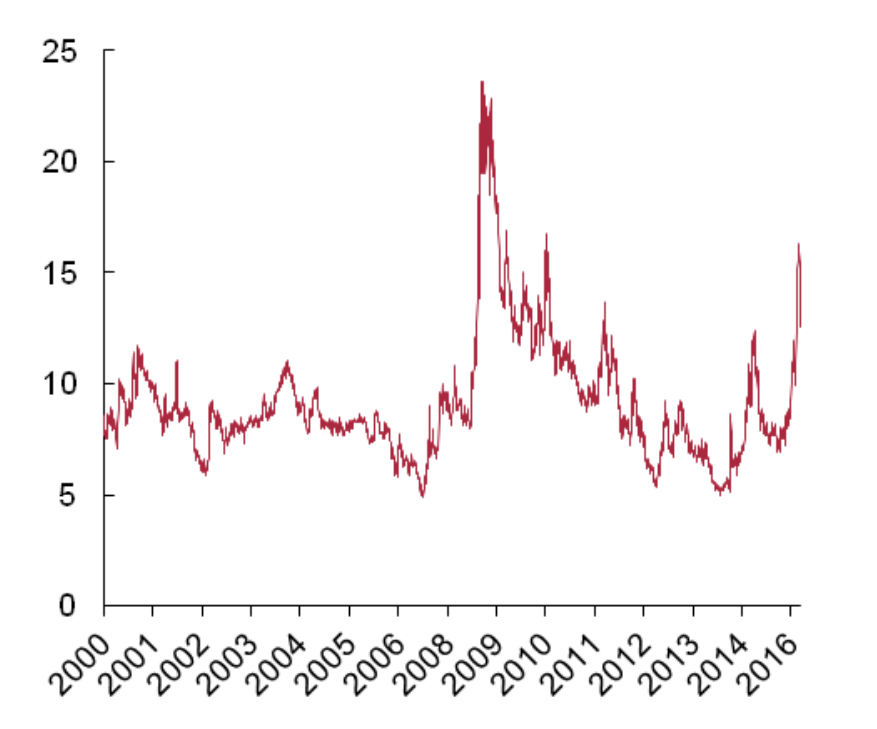

Source: Datastream

\section{Disentangling anticipated information on the shock from data}

A caveat to using market data to calibrate shocks is that the effects from the event that is being studied, in this case, a vote to leave, may already be factored in the data because of forward looking market expectations. If so, the shock in the event of a vote to leave may be smaller than expected as part of it is already priced in. By contrast, in the event of a vote to remain, one should allow for the possibility that some market movements will be unwound quickly.

An example were this caveat is taken into account can be found in Bank of England (2016), where they find half of the depreciation in sterling in the period between November 2015 and early May 2016 was driven by the expectation of a vote to leave. Their methodology relied on constructing a measure of referendum news flow and regressing sterling movements on that measure and other controls.

\section{Literature}

Another important method of calibration is to use existing estimates from the academic literature. In this case, care is of essence in mapping the estimates from the literature into the framework used to analyze the consequences of a vote to leave.

For example, to capture an increase in the cost of borrowing of the government, we shock the government bond premium in NiGEM, which acts as a wedge between the forward convolution of short- term interest rates and the interest rate on long-term government bonds. To calibrate the shock, we look at a number of academic studies. Joyce et al. (2011) look at the financial market impact of quantitative easing. Although this policy was one which affected the publicly available 
supply of gilts, rather than demand, the elasticities may be informative. They find that the reduction in the publicly available supply associated with the first quantitative easing programme decreased gilt yields by approximately 100 basis points. Studies by Breedon et al. (2014), Meaning and Zhu (2011) and Meaning and Warren (2015) find quantitatively similar results. Assuming similar elasticities for supply and demand, such a shift would imply a fall in demand of roughly 12 per cent of the total gilt market.

Our shock is therefore set to increase the premium on government bonds by 100 basis points in the third quarter of 2016 and stay at this elevated level for a further three quarters before receding back to its pre-referendum level over the next twelve months. There are several caveats to this shock which are discussed further in Baker et al. (2016).

\section{Ancillary analysis}

In some instances there is no clear mapping between existing estimates in the literature and the framework being used and further analysis must be carried in order to obtain a sensible calibration of the shock.

This was of particular relevance when calibrating the effects of heightened economic uncertainty on investment plans of firms. NiGEM's framework cannot follow the approach taken in DSGE models, such as the one by Bloom et al. (2014), where a rise in uncertainty is captured by shocking second order moments of the innovations, because the model does not model risk explicitly. Two different approaches have been used to deal with this problem. The first, implemented by HMT (2016), consists of estimating a vector auto-regression (VAR) that links a measure of uncertainty to a set of other economic variables including private consumption and investment. Once estimated, they obtain the impulse responses of private consumption and investment to a one standard deviation shock on the uncertainty measure and use those to calibrate endogenous ${ }^{6}$ shocks to private consumption and investment in NiGEM.

A second approach is to modify the existing model to better account for the channel and shock in question. As outlined in Appendix A, this was the route taken in the current work as the NiGEM model was expanded to include an uncertainty variable that acted as a shifter of investment demand.

\section{Transmission mechanisms and sensitivity analysis}

Given the large number of shocks that we consider, it is helpful to analyze the qualitative and quantitative implications of each of the shocks in isolation before turning to the full set of results that arise from layering the short-term shocks with the shocks that capture the long-term consequences of a change in regime. We also test the sensitivity of the results to variations of the magnitude of the shocks.

When we do this for the exchange rate in our EU referendum analysis, we find that the increase in risk causes the nominal sterling effective exchange rate to depreciate by around 20 per cent on impact, figure 2 . This depreciation is relatively short-lived with sterling returning broadly to its base level by the end of 2017 as the risk premium recedes. However, it does have consequences for the real economy. First, it drives the rate of inflation significantly higher (figure 3 ) as the fall in sterling pushes up the price of imported goods, which feeds directly in to the consumption basket. This

\footnotetext{
${ }^{6} \mathrm{NiGEM}$ allows for exogenous and endogenous shocks. Exogenous shocks supersede the equation being shocked by a set of values, while endogenous shocks just simply add an additional residual term -the shock- to the equation.
} 
external inflationary influence dominates in the early stages and the 12-month inflation rate jumps $2 \frac{1}{2}$ percentage points relative to the baseline. However, domestic inflationary pressure weakens as the unit total cost faced by producers falls, and within 4 quarters of the initial shock, these domestic factors outweigh import price movements resulting in a net disinflationary pressure.

Figure 2. Effective exchange rate (per cent difference from baseline)

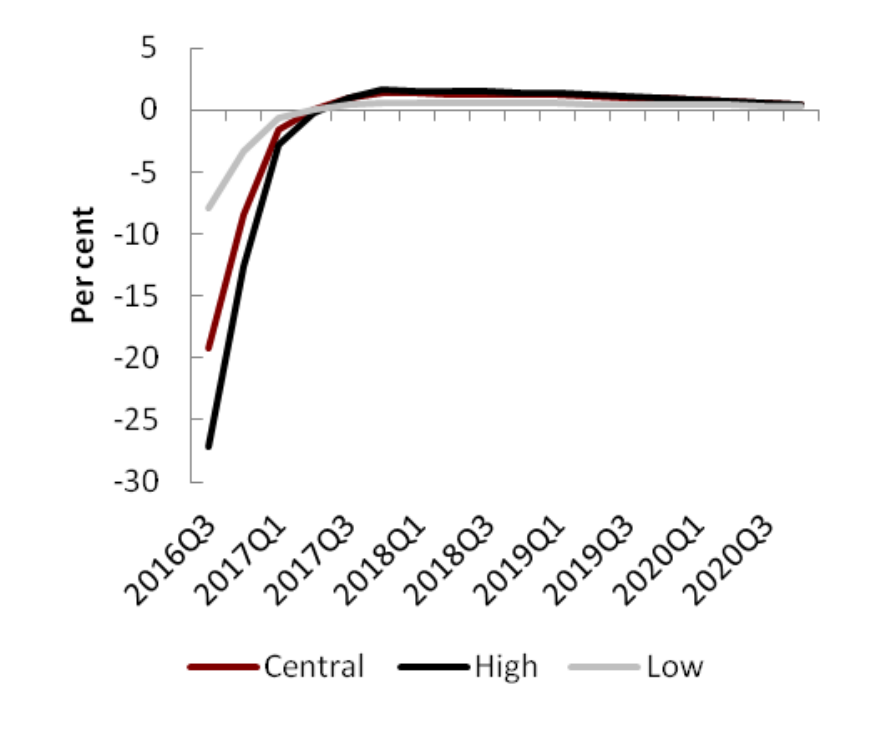

Source: NiGEM simulations.

Figure 3. Inflation rate (percentage points difference from baseline)

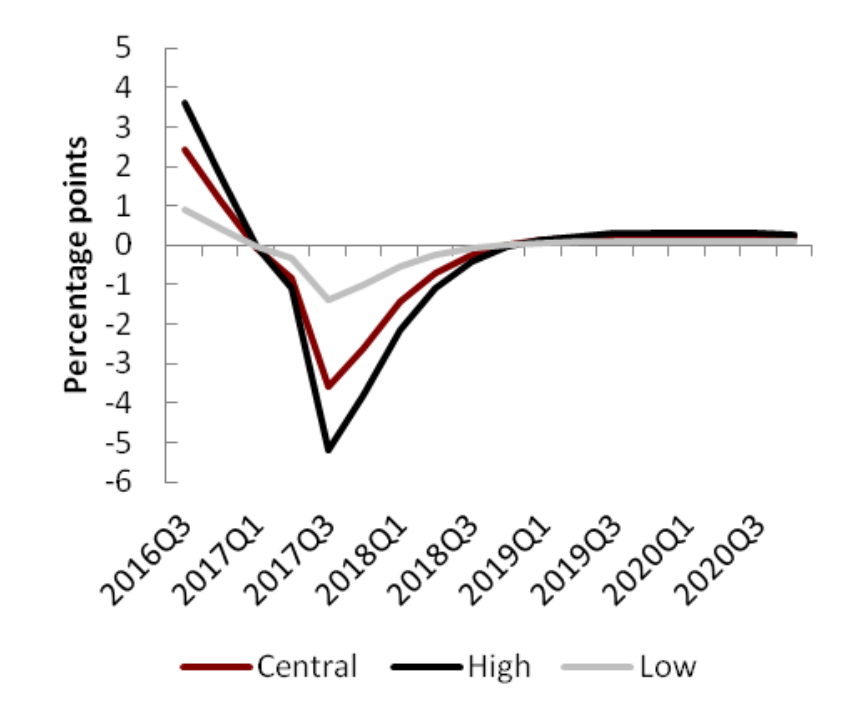

Source: NiGEM simulations.

The implications of this shock for output, in isolation, are firmly positive, figure 4 . The level of GDP is $1 \frac{1}{2}$ percent higher after 3 quarters compared to the baseline. The channel for this is simple: the depreciation provides a competitiveness advantage to UK exporters while dissuading imports. This results in a large positive contribution from net trade. It could thus be considered that the increase in the risk premium attached to sterling is a benign, if not largely beneficial shock to the UK economy. What we are missing in this partial analysis, obviously, are the associated negative effects which the depreciation of sterling is reacting to, and in some respects working to offset. By introducing these effects through the shocks described below, we build up a consistent and more comprehensive picture. 
Figure 4. GDP level (per cent difference from baseline)

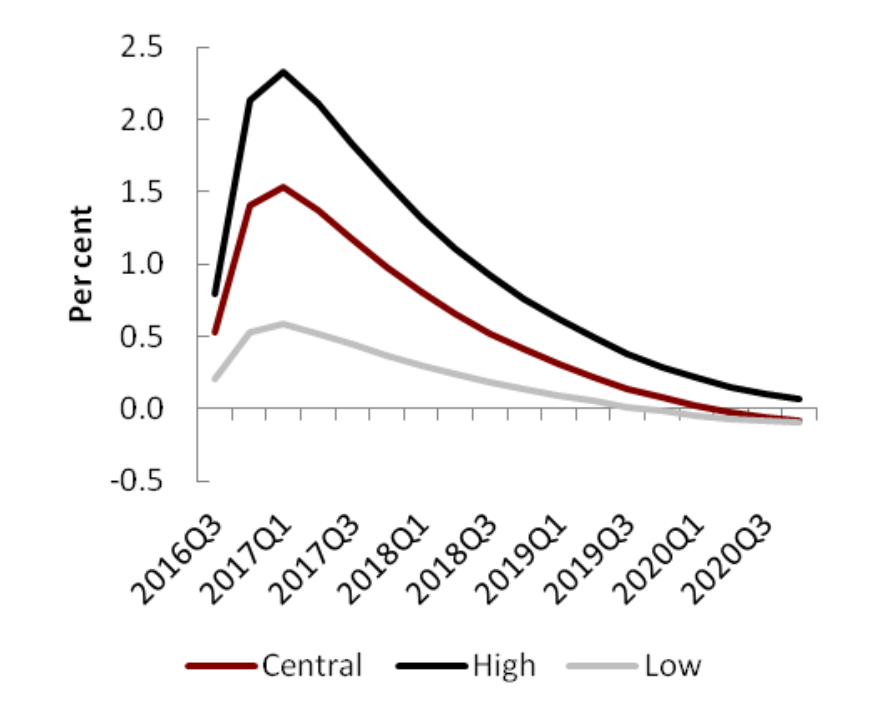

Source: NiGEM simulations.

Figures 2 to 4 plot two additional scenarios: High, in which we increase the initial size of the shock to be equivalent to that which occurred in the 2008 financial crisis, and Low, in which we assume that the risk premium widens by approximately $1 / 3$ of the size of our central case. This gives us a range for the expected depreciation of between 8 and 27 per cent, and of the impact on output of between $1 / 2$ and $21 / 2$ per cent. For inflation, the Low case sees both a less pronounced inflation upon impact, 1 percentage point, compared to almost 4 percentage points in the High case, and also a shallower disinflation in subsequent periods.

Looking at the effects of increased cost of financing for government, firms and households, we find that private investment declines by 8 per cent by the end of 2017, figure 5 . This combines the effects of the shock on the government bond premium, which feed into the user cost of capital of firms via its impact on the long-term interest rate, and the shock on corporate bond spreads and equity risk premium. Private consumption reacts more slowly to the increased cost of borrowing, reaching a trough of 1 per cent below the baseline by mid-2018, figure 6 .

Figure 5. Private sector investment (per cent difference from baseline)

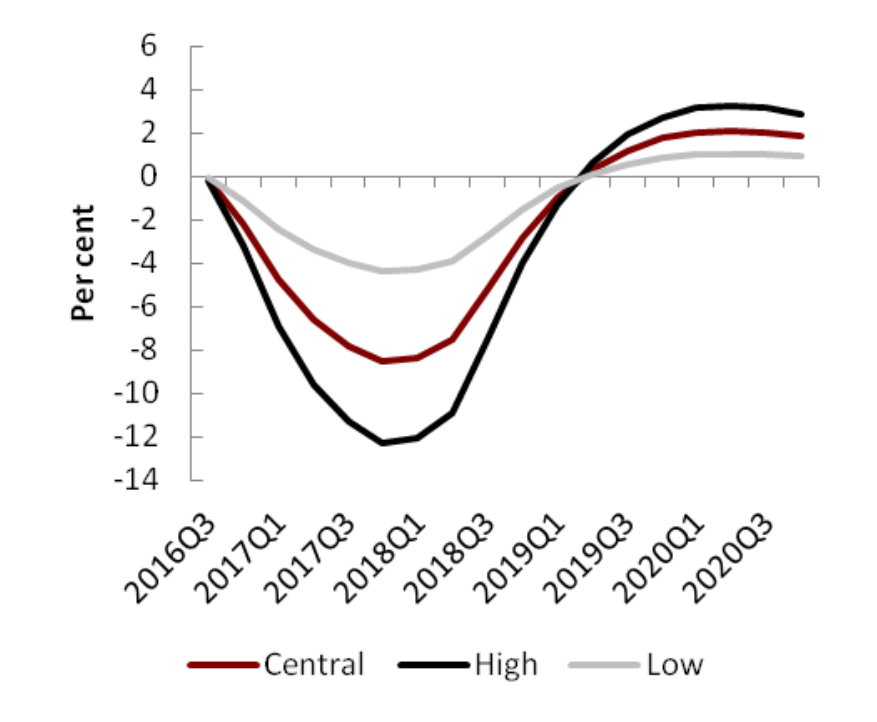

Source: NiGEM simulations. 
Figure 6. Household consumption (per cent difference from baseline)

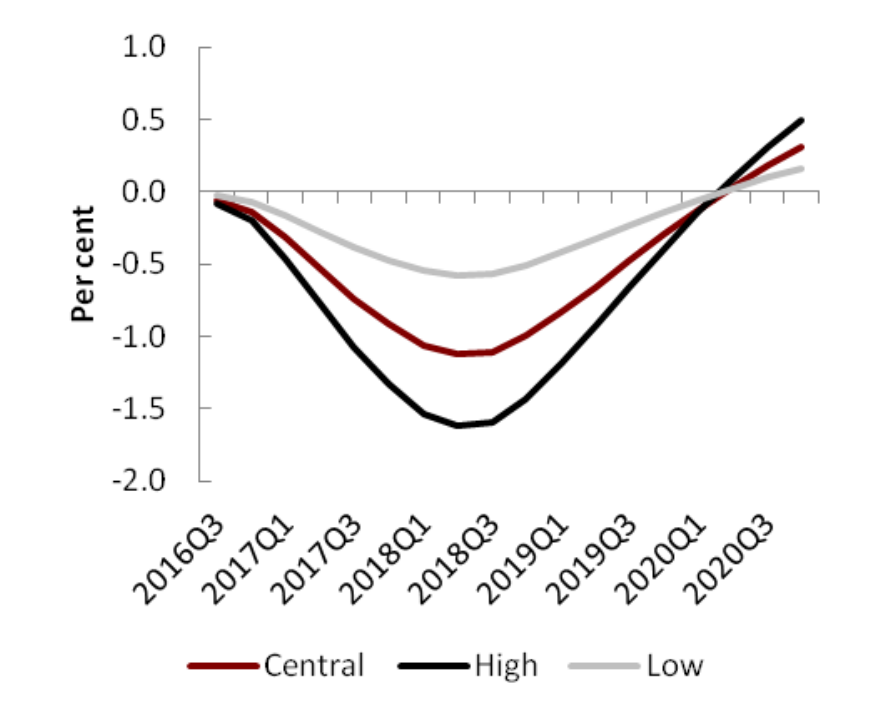

Source: NiGEM simulations.

As a result of the contraction in credit and the rise in long-term rates, output declines, reaching a trough of 1 per cent in 2018, figure 7. Such decline in activity is accompanied by a gradual reduction in the rate of consumer price inflation, figure 8 . As opposed to the exchange rate shock, where the inflation rate reacted quickly to the increase in the cost of imports following sterling depreciation, the impact on the rate of consumer price inflation in this scenario comes with a lag caused by nominal rigidities embedded within the model.

Figure 7. GDP level (per cent difference from baseline)

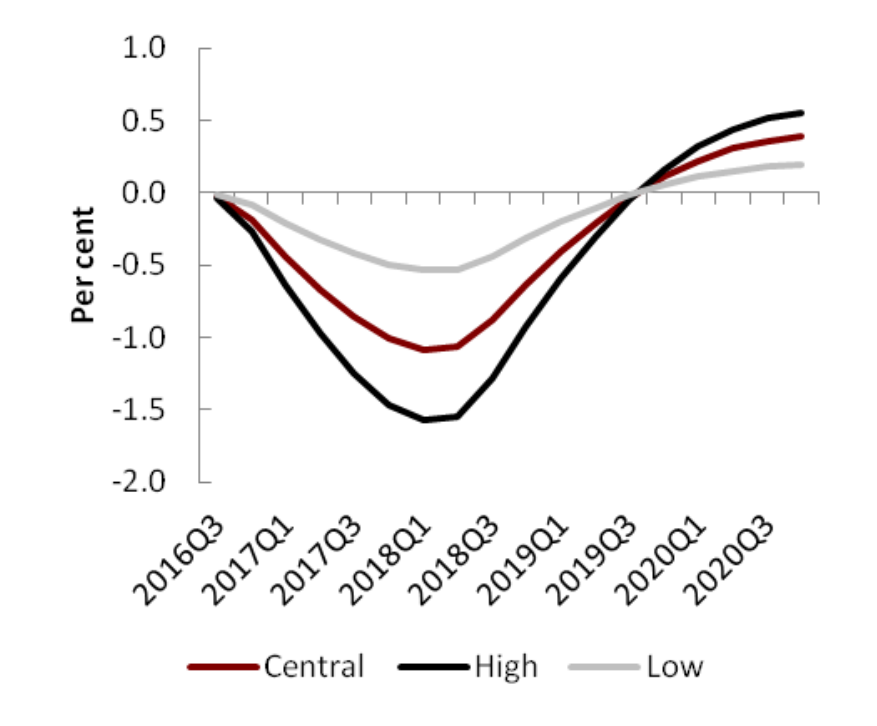

Source: NiGEM simulations. 
Figure 8. Inflation rate (percentage points difference from baseline)

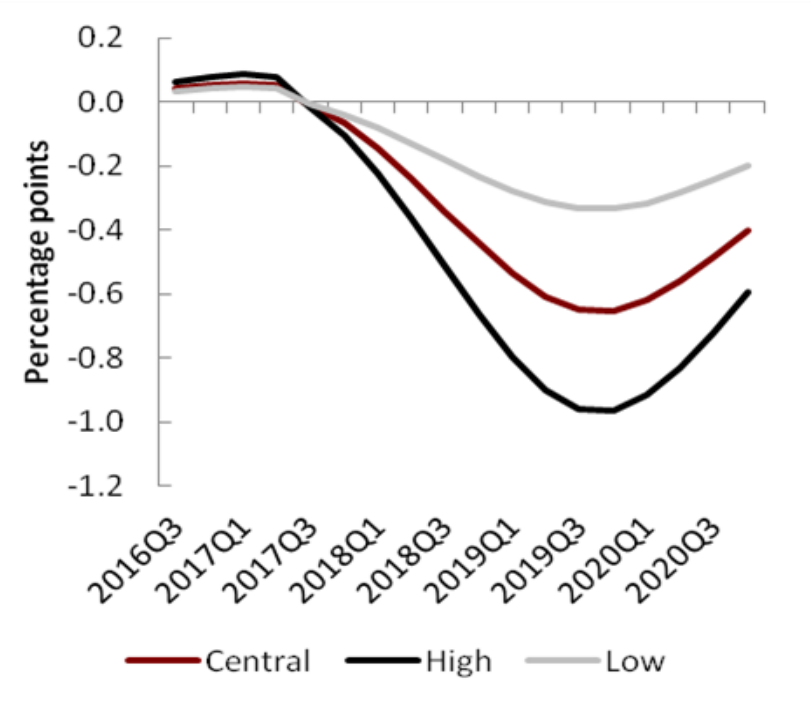

Source: NiGEM simulations.

Finally, when we look in isolation at the effects of a shock on uncertainty, we find that private investment falls sharply with a contraction of 7 per cent on impact widening to almost 9 per cent the following quarter, figure 9 . As the shock dissipates, investment quickly returns to the long-run equilibrium. The contraction in investment has a direct effect on output and real GDP falls by 0.6 percentage point on impact and reaches a trough of almost 0.8 percentage point below baseline in 2017 , figure 10. By 2019, as the shock recedes, output returns to base. The decline in activity deducts 0.2 and 0.3 percentage point from the rate of consumer price inflation in 2017 and 2018 respectively, figure 11 .

Figure 9. Private sector investment (per cent difference from baseline)

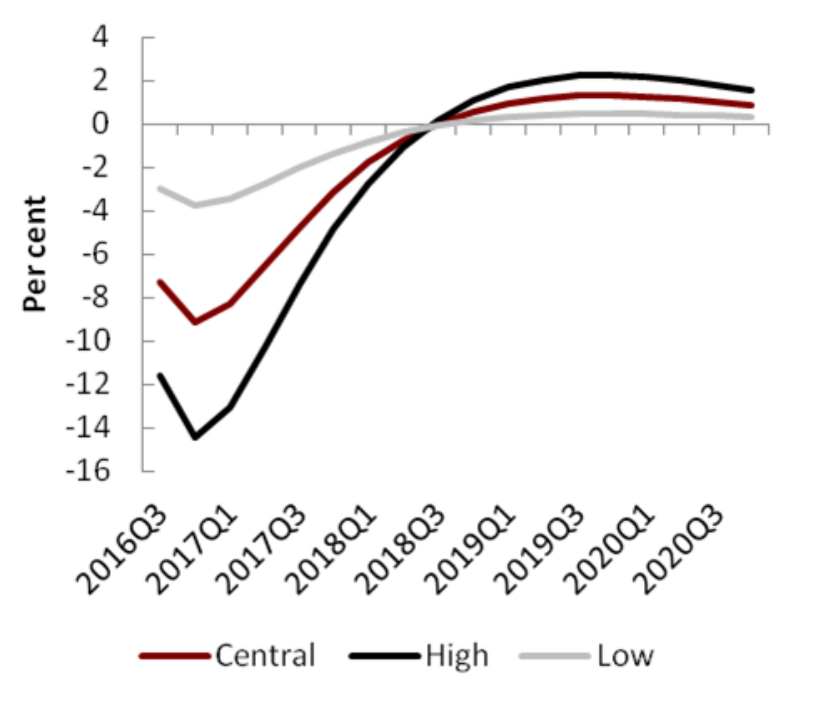

Source: NiGEM simulations. 
Figure 10. GDP level (per cent difference from baseline)

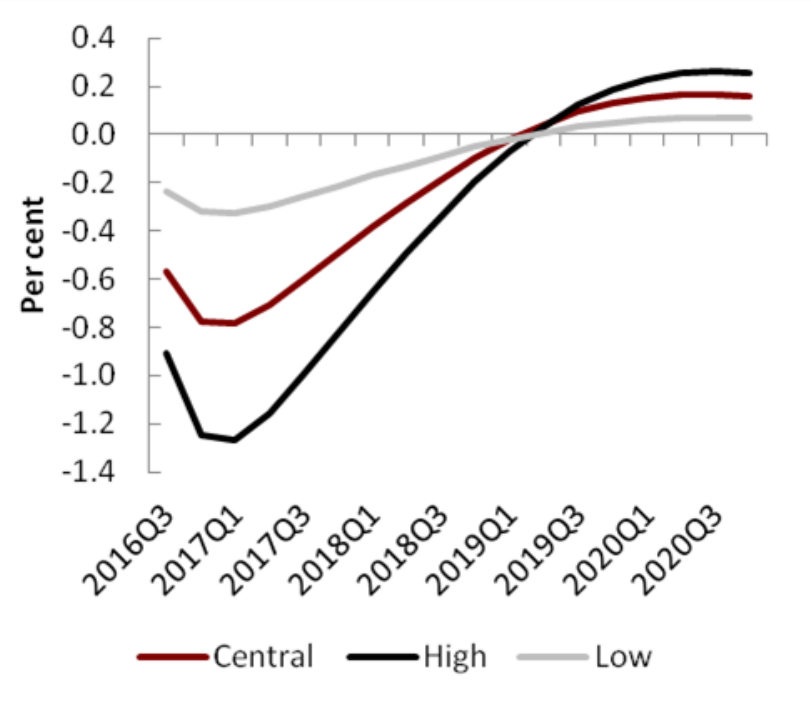

Source: NiGEM simulations.

Figure 11. Inflation rate (percentage points difference from baseline)

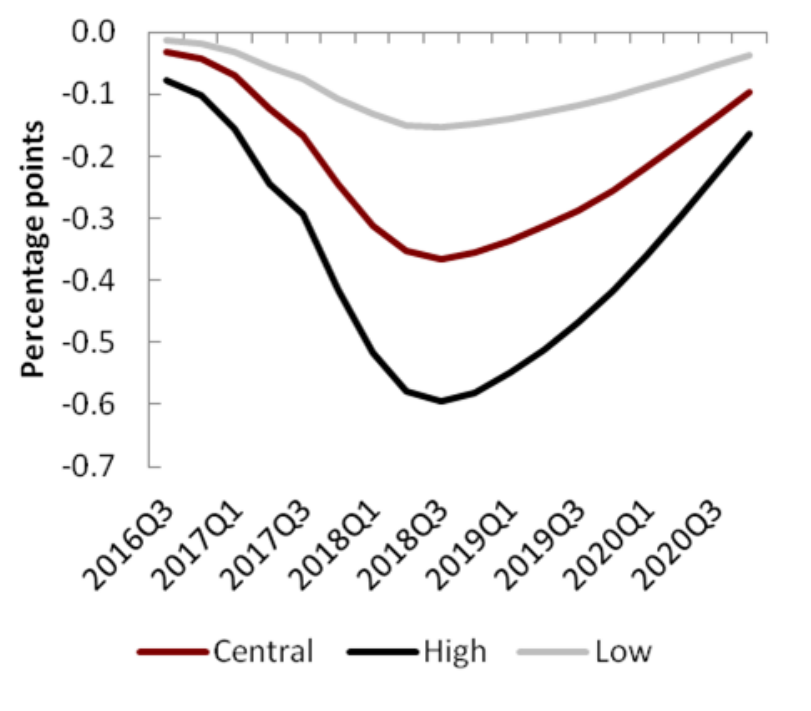

Source: NiGEM simulations.

The direct effect of uncertainty on investment is modest compared to other quantitative analyses. Bloom et al. (2014) for example simulate the effects of uncertainty on investment using a DSGE model calibrated using data on US firms' investment behaviour. They find that a 91 per cent increase in uncertainty results in a fall in investment of around 18 per cent. Similarly, Bond and Cummins (2004) investigate the effects of increasing uncertainty as measured by the standard deviation of daily stock returns on publicly traded US firms. They find that a 15 per cent increase in uncertainty reduces investment by 6 per cent. To check the robustness of our results, we run a conservative and an extreme uncertainty shock. The conservative shock is half the size of the central shock and the extreme shock is 50 per cent larger. The responses on investment and output are proportional to the shock size.

\section{Combining the shocks for a more complete counterfactual}

None of the shocks detailed above persist beyond the two-year negotiating period. This may seem a generous assumption, considering the potentially protracted nature of negotiations not only with the EU, but also with the rest of the UK's trading partners, both old and new. However, beyond this horizon we deem it likely that much of the uncertainty will have dissipated and markets will have a 
much clearer idea of the direction of both the negotiations, and the UK economy, are taking, even if not all of the issues are fully resolved.

The counterpart to this waning uncertainty is that as decisions are made and final positions taken, the more structural and permanent changes to the UK economy come into effect. As our uncertainty and premia shocks fade through 2017 and early 2018 there is a gradual introduction of changes to the UK's share of export markets, and eventually the imposition of tariffs. These include reductions in trade with the EU, foreign direct investment, and net fiscal contribution to the EU. The long-run shocks implemented in this analysis correspond to the optimistic 'WTO' scenario in Ebell and Warren (2016), in which there is no membership in free trade agreements for goods or services with the EU and no financial passporting.

The ultimate long-run assumptions have consequences for our transition period. The forwardlooking nature of agents means that, although subject to uncertainty, they do foresee, at least in part, the shifts that are ahead of them. The negative fallout from these later shocks in fact acts to weigh down on the performance of the UK even before they come in to effect. The timing of the shocks is therefore important and will have an effect on the overall outcome. Figure 12 summarises the timing of the shocks. In contrast to our analysis, the OECD's short-run analysis was done under the assumption of backward-looking agents, while their long-run analysis assumed forward-looking agents.

Figure 12. Timing of the shocks

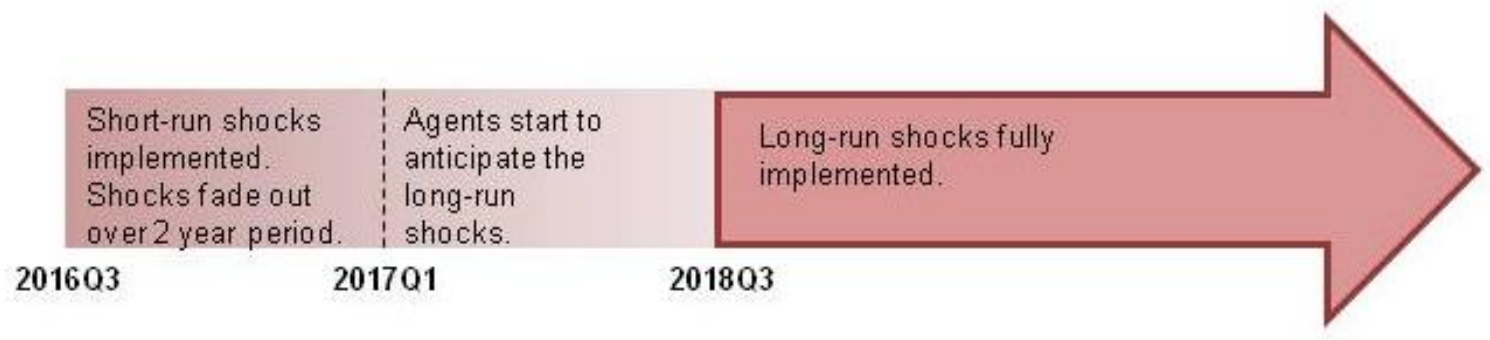

The results of combining the short run shock discussed above with the long-run shocks from Ebell and Warren (2016), derived on the assumptions within their WTO variant, are presented in an annual frequency in table 2

Table 2. Summary: optimistic WTO variant

\begin{tabular}{lrrrrr}
\hline & 2016 & 2017 & 2018 & 2019 & 2020 \\
\hline \hline GDP - \% change from baseline & -0.2 & -1.0 & -2.3 & -2.8 & -2.5 \\
Consumption - \% change from baseline & -0.1 & -1.2 & -1.7 & -2.1 & -2.4 \\
Investment (PSI) - \% change from baseline & -4.8 & -15.0 & -12.8 & -8.1 & -4.6 \\
Real consumer wages - \% change from baseline & -0.6 & -1.9 & -2.1 & -2.9 & -3.5 \\
Output per hour worked - \% change from baseline & -0.4 & -1.1 & -1.6 & -1.6 & -1.8 \\
Unemployment, \% - change in levels & -0.2 & -0.1 & 0.7 & 1.2 & 0.8 \\
Inflation - change in levels & 0.7 & 2.2 & 1.3 & 1.3 & 0.4 \\
Bank rate, \% - change in levels & 0.0 & 0.0 & 0.2 & 0.5 & 0.0 \\
Long rate, \% - change in levels & 0.5 & 1.0 & 0.1 & -0.1 & -0.1 \\
Effective direct tax rate, \% - change in levels & 0.0 & 0.1 & 0.2 & 0.4 & 0.6 \\
\hline
\end{tabular}

Note: numbers are rounded to one decimal point. 


\section{The outlook after a vote to leave the EU}

Figure 13 shows that consumer price inflation jumps on impact by $1 \frac{1}{2}$ percentage points. This is driven predominantly by the large depreciation of sterling, figure 14 , which is itself a result of the widening of the risk premium. With the sterling effective exchange rate falling by around 20 per cent on impact and remaining 14 per cent below the counterfactual in 2017, import prices rise and generate inflationary pressure.

Figure 13. Inflation rate (percentage points difference from baseline)

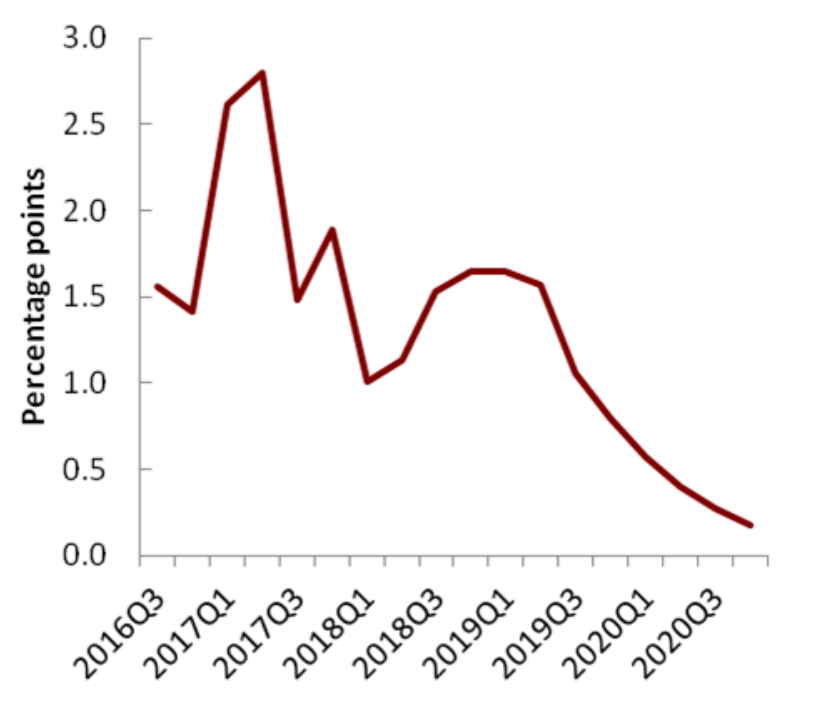

Source: NiGEM simulations.

Figure 14. Effective exchange rate (per cent difference from baseline)

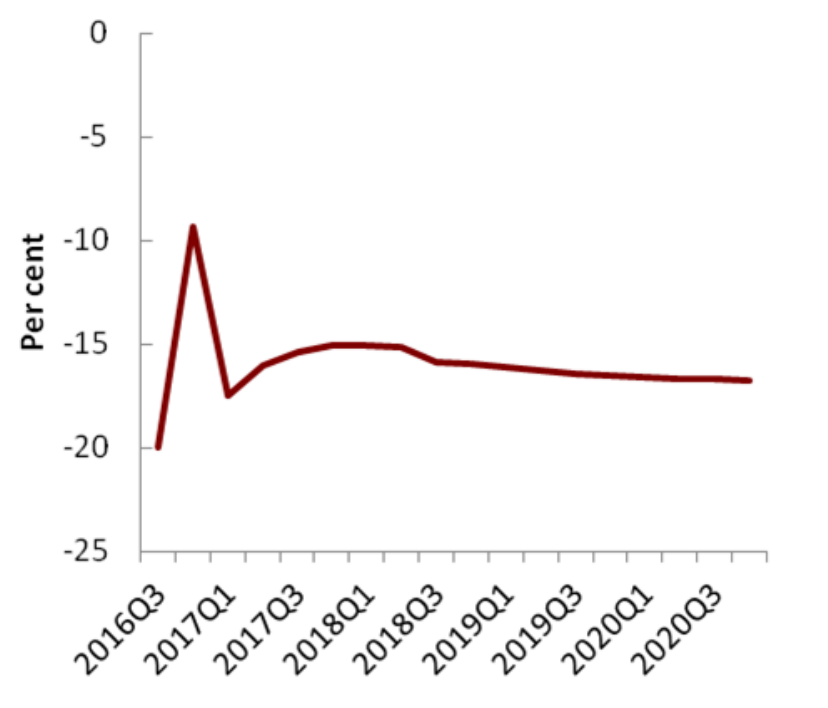

Source: NiGEM simulations.

Real GDP is broadly unaffected in 2016 as the decline in domestic demand is offset by a marginally positive net trade contribution, figure 15 . This comes from a temporary terms of trade improvement as the depreciation of sterling boosts the price competitiveness of UK exporters, while reducing the attractiveness of imports to UK consumers. This is however short-lived and by 2017 domestic factors dominate, causing the level of GDP to be just over 1 per cent lower than in our baseline forecast. By 2018 GDP is 2.3 per cent below our baseline, 1.8 percentage points of which are directly due to the short-run shocks with the remaining 0.5 per cent arising from the transition to the long-run. 
Figure 15. GDP level (per cent difference from baseline)

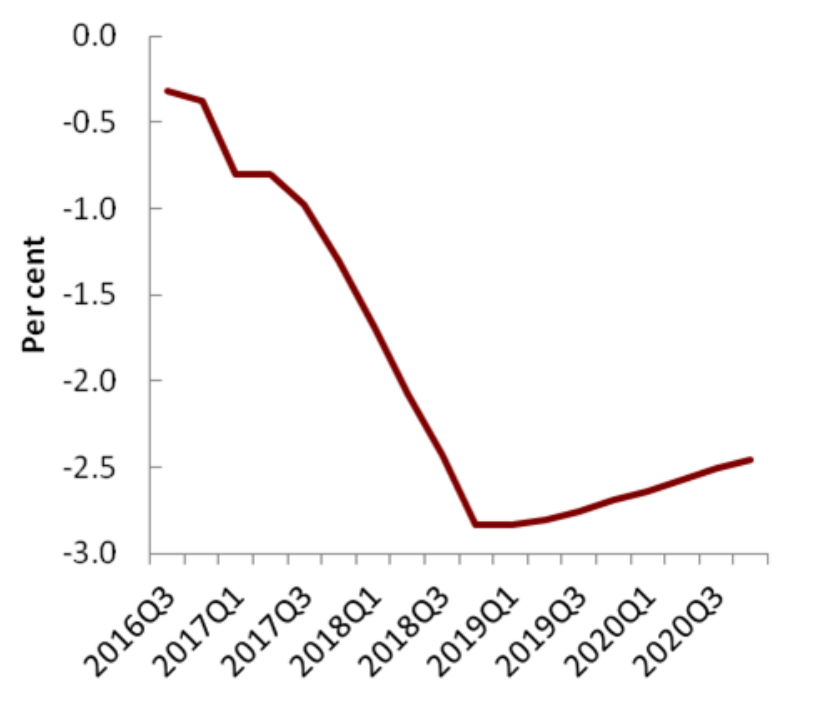

Source: NiGEM simulations.

Investment falls dramatically, figure 16. This comes through a number of channels. First is the direct impact of uncertainty. This shock in isolation results in a drop in business investment of just over 10 per cent in the third quarter of 2016, compared to the baseline case of a vote against leaving the EU, rising to $12 \frac{1}{2}$ per cent the following quarter before gradually returning to baseline levels. Second, we also observe a substitution effect between labour and capital as inputs t production, which further weighs on investment. Falling real producer wages make labour a more cost effective input, while widening borrowing premia push up the user cost of capital, reducing the attractiveness of capital and lowering the optimal capital/output ratio. At the same time, consumption is hit by lower real incomes alongside increased costs of credit and relative reductions in wealth as house prices fall, figure 17.

Figure 16. Private sector investment (per cent difference from baseline)

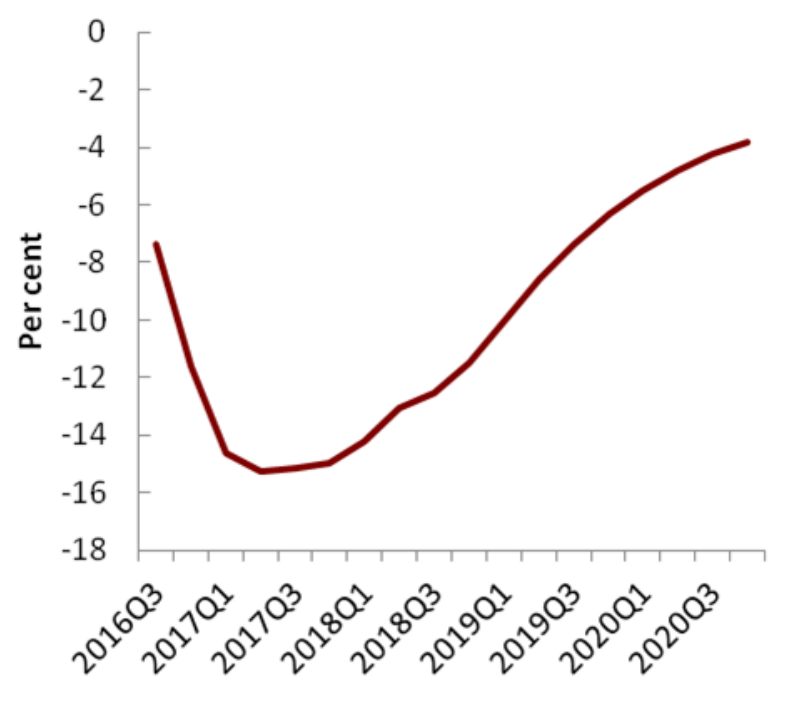

Source: NiGEM simulations. 
Figure 17. Household consumption (per cent difference from baseline)

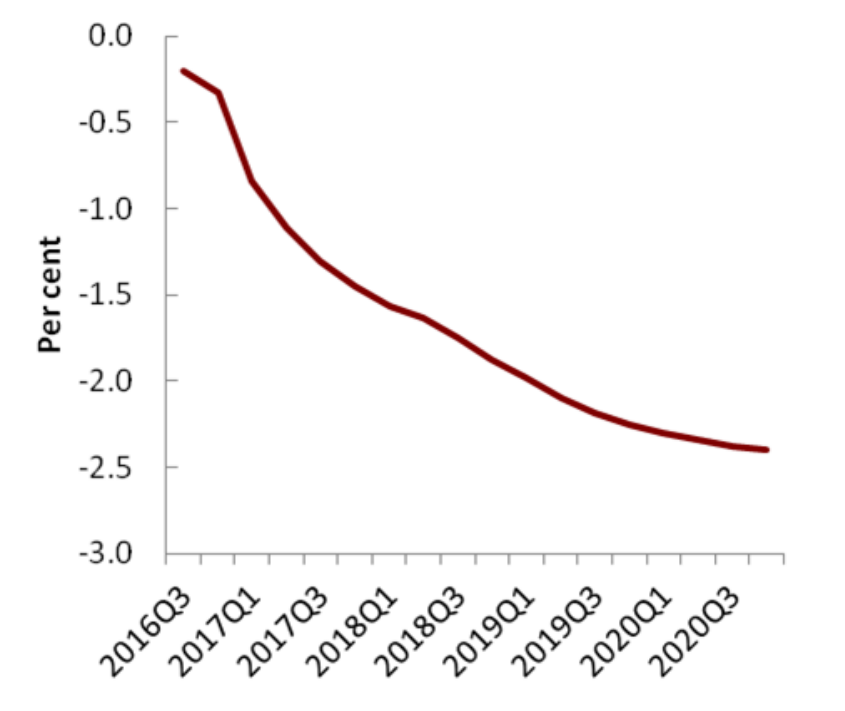

Source: NiGEM simulations.

\section{Testing sensitivity to policy reactions}

The response of policymakers over this period is extremely hard to predict. With this in mind, in our baseline counterfactual exercise we assume that the Monetary Policy Committee (MPC) chooses to wait for the uncertainty to subside before making a decisive policy move. As such, Bank rate is held fixed for the first two years of the simulation, until the third quarter of 2018. From this point on we assume the MPC reacts to the evolution of the economy by following a Taylor rule. This means that they set the short-term nominal interest rate in response to fluctuations in the output gap and deviations of inflation from its 2 per cent target rate. We parameterise this policy rule using the coefficients used in the Bank of England's own COMPASS model, as detailed in Burgess et al. (2013).

An interesting exercise is to see what effect our assumption of a fixed Bank Rate would have, compared to a world in which the MPC sets Bank Rate in line with its policy rule from the first instance. In this world, the policy rule as defined above would dictate that the Bank of England would loosen the stance of monetary policy by cutting Bank Rate by between 50 and 100 basis points relative to the counterfactual over the course of 2016 and 2017, figure 18. Based on the current market expectation of the path of Bank Rate, this would imply a move to zero, if not marginally negative, nominal interest rates ${ }^{7}$. To do this at a time when inflation is above target, as our scenario would suggest, may appear counterintuitive. However, as outlined previously, the bulk of the inflationary pressure stems from the sharp depreciation of sterling rather than a boom in domestic price pressures, which in fact would be likely to be softening. Therefore it may be that the MPC chooses to look through the temporary inflationary period in order to stimulate underlying demand and meet the mandated target more sustainably in the medium to long-term.

\footnotetext{
${ }^{7}$ The depth of the cut in Bank Rate may appear overstated by figure 18, as it shows the absolute difference from a baseline which assumes Bank Rate begins to rise from the final quarter of 2016. This means that policy is in fact in part looser just by holding rates lower for longer, reducing the actual size of the implied cut. However, market expectations are for Bank Rate to be flat until the end of 2020, and so the path shown in figure 18 would imply a reduction in Bank Rate to approximately $-1 / 2$ per cent per annum at the most extreme.
} 
Figure 18. Bank rate (percentage points difference from baseline)

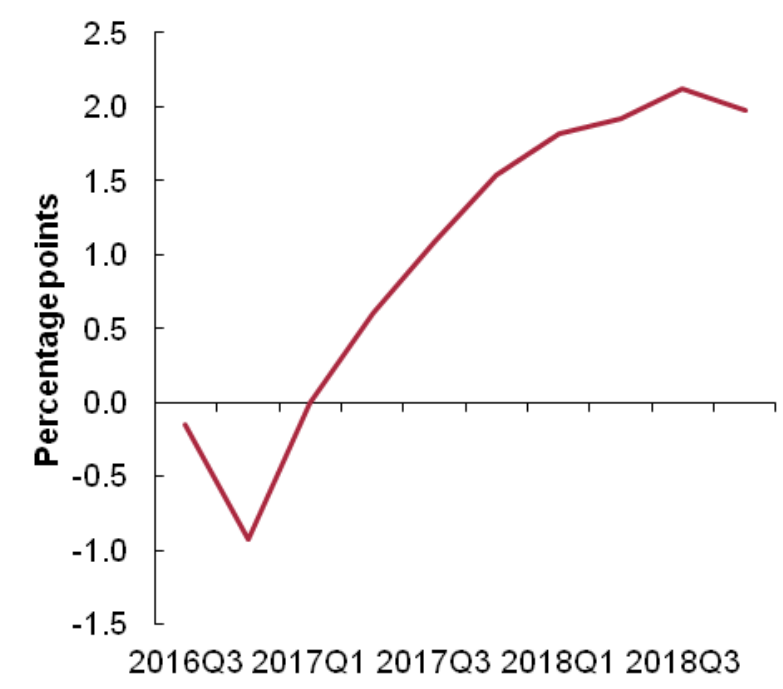

Source: NiGEM simulations.

We can see in figures 19-20 that allowing monetary policy to actively stabilise the economy from the off makes little difference to our central narrative. In fact, although it does manage to reduce the spike in inflation in 2017 by around $1 / 2$ percentage point, there is a trade-off in the shape of a marginally weaker outlook for GDP.

Figure 19. GDP level with and without an active monetary policy response (per cent difference from baseline)

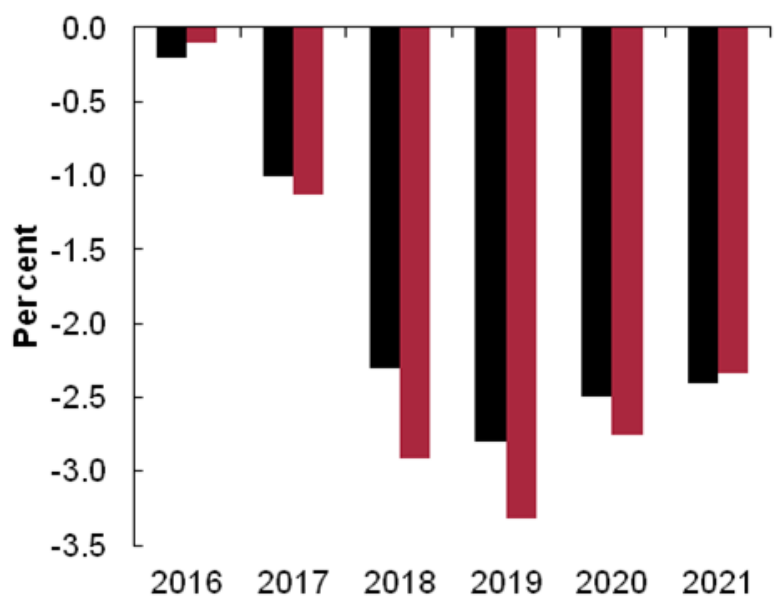

-Bank Rate fixed for 2 years active monetary policy

Source: NiGEM simulations

Within our simulation exercise, we make no allowance for unconventional monetary policies. If the MPC members feel they wish to stimulate the economy without implementing a negative policy rate, they have alternative policy instruments, most notably a fresh round of quantitative easing. By compressing the premia inherent in government bond yields, quantitative easing may be able to lower interest rates at the longer end of the yield curve and provide some additional stimulus. 
Figure 20. Inflation rate with and without an active monetary response (percentage points difference from baseline)

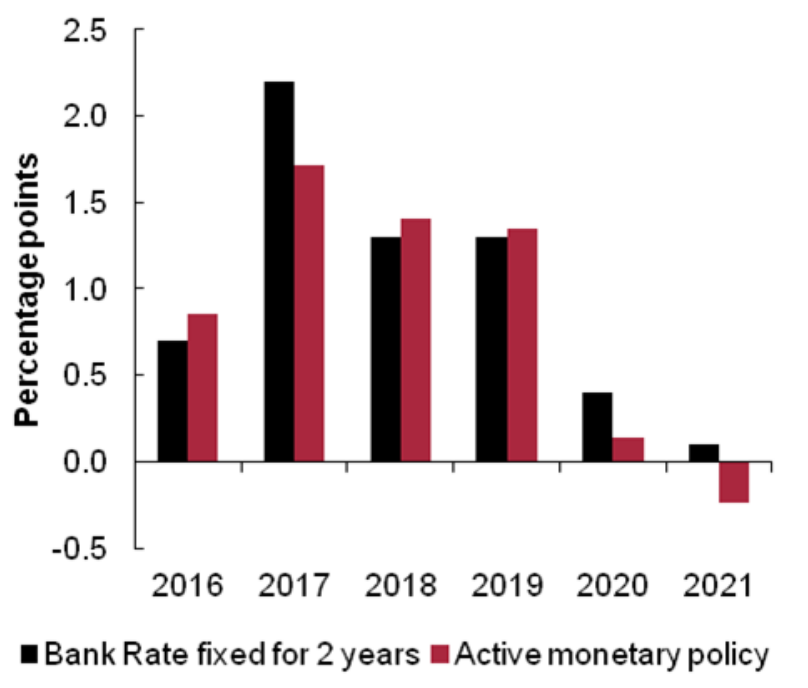

Source: NiGEM simulations.

\section{Conclusions}

This paper has provided a general framework for constructing an informative counterfactual path for the economy in light of a large socio-economic event that may represent a significant change in regime. While such an event represents a complex shock ill-suited for direct introduction to an economic model, we advocate breaking down the deep underlying shocks into a series of more tractable shocks, consistent with the particular model being employed. These shocks can then be calibrated to plausible levels through a range of techniques, and applied in isolation to give a clear exposition of the relevant transmission mechanisms at work. Finally the series of shocks can be introduced to a single simulation exercise, taking account of agents' expectations and the timeline of the event itself.

Applying this method to the contemporary example of the United Kingdom's referendum on the European Union, we characterise the underlying shock by short-run innovations to the level of uncertainty, and risk premia associated with the exchange rate and borrowing costs faced by the public and private sector.

Our analysis shows that the decision to leave the EU would be detrimental to UK GDP when compared with a path in which the UK remained a member. There would also be a large increase in inflationary pressure driven predominantly by the depreciation of the effective sterling exchange rate.

Ultimately, economic models should not be seen as a crystal ball, and a modelling exercise such as the one presented here should not be expected to give precise point estimates of the future path of the economy. However, when carried out in an open and transparent way, and if built on robust assumptions, they can provide a valuable insight into the direction and broad magnitude of impact of specific events. In this way economic modelling can, and should continue to, play an important role in debates around large socio-economic events. 


\section{References}

Abel, A.B. (1983), 'Optimal investment under uncertainty', The American Economic Review, 73(1), pp. 228-33.

Baker, J., Carreras, O., Ebell, M., Hurst, I., Kirby, S., Meaning, J., Piggott, R. and Warren, J. (2016), 'The short-term economic impact of leaving the EU', National Institute Economic Review, 236, pp. 108-120.

Bank of England, (2016), 'Inflation report', May 2016.

Barrell, R. and Dury, K. (2003), 'Asymmetric labour markets in a converging Europe: do differences matter?', National Institute Economic Review, 183, pp. 56-64.

Barrell, R. and Pain, N. (1997), 'Foreign direct investment, technological change, and economic growth within Europe', Economic Journal, 107, pp. 1770-76.

Barrell, R. and Riley, R. (2006), 'Is UK business investment unusually weak?', National Institute Economic Review, 196, pp. 60-62.

Bean, C. (1981), 'An econometric model of manufacturing investment in the UK', Economic Journal, 91, pp. 72-93.

Beaulieu, M.C., Cosset, J.C., and Essaddam, N. (2005), 'The impact of political risk on the volatility of stock returns: the case of Canada', Journal of International Business Studies, pp. 701-18.

Bernanke, B.S. (1983), 'Irreversibility, uncertainty, and cyclical investment', The Quarterly Journal of Economics, 98(1), pp. 85-106.

Bloom, N. (2009), 'The impact of uncertainty shocks', Econometrica, 77(3), pp. 623-85.

Bloom, N., Floetotto, M., Jaimovich, N., Saporta Eksten, I. and Terry, S. (2014), 'Really uncertain business cycles', US Census Bureau Center for Economic Studies, Paper No. CES-WP-14-18.

Bloomberg (2016), 'The impact of 'Brexit' on Sovereign Ratings for the U.K.', February 2016.

Bond, S. and Cummins, J. (2004), 'Uncertainty and investment: an empirical investigation using data on analysts' profits forecasts', Finance and Economics Discussion Series 2004-20, Board of Governors of the Federal Reserve System (US).

Breedon, F., Chadha, J. and Waters, A (2012), 'The financial market impact of UK quantitative easing', Oxford Review of Economic Policy, 28(4), 702-728.

Burgess, S., Fernandez-Corugeda, E., Groth, C., Harrison, R., Monti, F., Theodoridis, K. and Waldron, M. (2013), 'The Bank of England's forecasting platform: COMPASS, MAPS, EASE and the suite of models', Bank of England Working Paper No. 471.

Chadha, J. S., Macmillan, P., \& Nolan, C. (2007), 'Independence day for the 'Old Lady': A natural experiment on the implications of central bank independence', The Manchester School, 75(3), 311327.

Chen, S. W. (2014), 'Testing for fiscal sustainability: New evidence from the G-7 and some European countries', Economic Modelling, 37, 1-15. 
Davies, M. and Panetta, F. (2011), 'How does sovereign risk affect bank funding conditions? What can policymakers do?', VoxEU. org, 26.

Dixit, A. (1989), 'Entry and exit decisions under uncertainty', Journal of political Economy, pp. 62038.

Durnev, A. (2010), 'The real effects of political uncertainty: elections and investment sensitivity to stock prices', SSRN Working Paper Series.

Ebell, M. and Warren, J. (2016), 'The long-term economic impact of leaving the EU', National Institute Economic Review, 236, pp. 121-138.

Fernández-Villaverde, J., Guerrón-Quintana, P., Kuester, K. and Rubio-Ramírez, J. (2015), 'Fiscal volatility shocks and economic activity', The American Economic Review, 105(11), pp. 3352-84.

Fitch Ratings (2015), 'Fitch: Brexit Vote Would Be Moderately Credit Negative for UK', 14 December 2015.

Haddow, A., Hare, C., Hooley, J. and Shakir, T. (2013), 'Macroeconomic uncertainty; what is it, how can we measure it and why does it matter?', Bank of England Quarterly Bulletin, 53, 2, pp. 100-109.

Hallett, A. H., Ma, Y., \& Melitz, J. (1996), 'Unification and the policy predicament in Germany', Economic Modelling, 13(4), 519-544.

Hartman, R. (1972), 'The effects of price and cost uncertainty on investment', Journal of Economic Theory, 5(2), pp. 258-66.

HMT (2016), 'HM Treasury analysis: the immediate economic impact of leaving the EU', May 2016.

Joyce, M., Lasaosa, A., Stevens, I. and Tong, M. (2010), 'The financial market impact of quantitative easing', Bank of England Working Paper No 393.

Julio, B. and Yook, Y. (2012), 'Political uncertainty and corporate investment cycles', The Journal of Finance, 67(1), pp. 45-83.

Kierzenkowski, R., Pain, N., Rusticelli, E., and Zwart, S. (2016). 'The Economic Consequences of Brexit: a Taxing Decision'. OECD economic policy paper, April 2016, No. 16.

Leahy, J. and Whited, T.M. (1996), 'The Effects of uncertainty on investment: some stylized facts', Journal of Money, Credit, and Banking, 28(1), pp. 64-83.

Meaning, J. and Warren, J. (2015), 'The transmission of unconventional monetary policy in UK debt markets', National Institute Economic Review, 234, pp. R40-R47.

Meaning, J. and Zhu, F. (2011) 'The impact of recent central bank asset purchase programmes', The Bank for International Settlements Quarterly Review, December.

Moody's (2015), 'EU exit would be negative for UK economy, but credit impact would depend on policy', 3 December 2015.

Oi, W.Y. (1961), 'The desirability of price instability under perfect competition', Econometrica, 29(1), pp. 58-64.

Pain, N. and Young, G. (2004), 'The macroeconomic impact of UK withdrawal from the EU', Economic Modelling, 21, pp. 387-408. 
Pindyck, R.S. (1988), 'Irreversible investment, capacity choice, and the value of the firm', The American Economic Review, 78(5), pp. 969-85.

Stock, J.H. and Watson, M.W. (2002), 'Forecasting using principal components from a large number of predictors', Journal of the American Statistical Association, 97, 460, pp. 1167-79. 


\section{Appendix A}

We have introduced uncertainty in the model as a variable that captures shifts in investment demand. To do so, we extend our estimated error correction model of business investment using a measure of uncertainty as a variable to help explain short-run deviations from the long-run relationship. According to standard economic theory, demand for capital as a factor of production is determined by the real user cost of capital, the production technology and the mark-up over unit costs. We follow Barrell and Riley (2006), complementing their specification with a measure of uncertainty and capacity utilisation. We have assumed a CES technology with elasticity of substitution $\sigma$, a constant mark-up over unit costs and zero capital augmenting technological progress. We use the result that equilibrium capital stock and investment grow at the same rate in the long-run (as in Bean 1981) to write the long-run relationship between business investment (IB), output (Y) and the user cost of capital (USER) as

$$
\log \mathrm{IB}_{\mathrm{t}}=\mathrm{cons}+\log \mathrm{Y}_{\mathrm{t}}-\sigma \log \mathrm{USER}_{\mathrm{t}}
$$

where IB is business investment (volumes), $\mathrm{Y}$ is output (volumes) and USER is the real user cost of capital. The results from estimating equation ( 2 ) via OLS can be found in Table 3.

Table 3. OLS regression outcome of equation ( 2 )

\begin{tabular}{lcc}
\multicolumn{1}{c}{ Parameter } & Estimate & Std. Error \\
\hline cons & $-2.651^{* * *}$ & 0.050 \\
$\sigma$ & $-0.153^{* * *}$ & 0.031 \\
& & \\
R-squared & 0.155 & \\
Adjusted R-squared & 0.148 & \\
SE & 0.101 &
\end{tabular}

Sample 1981q1-2015q1

*** indicates significance at the $1 \%$ level

We estimate the following error-correction equation for business investment around the long-run relationship in ( 2 ), including a measure of uncertainty (UNCERT) and capacity utilisation (CU):

$$
\Delta \log \mathrm{BB}_{\mathrm{t}}=\text { cons }+\alpha_{\mathrm{ECM}} \text { resids }_{\mathrm{t}-1}+\alpha_{\mathrm{CU}} \mathrm{CU}_{\mathrm{t}}+\alpha_{\mathrm{UN}} \mathrm{UNCERT}_{\mathrm{t}}+\text { dynamics }
$$

where resids are the residuals from estimation of ( 2 ). Table provides the outcome of the OLS regression of equation ( 3 ). 
Table 4. Results from estimation of equation ( 3 )

\begin{tabular}{|c|c|c|c|}
\hline Parameter & Estimate & Std. Error & \\
\hline cons & $-0.316^{* *}$ & -2.205 & \\
\hline$\alpha_{C U}$ & $0.306^{* *}$ & 2.224 & \\
\hline$\alpha_{\mathrm{ECM}}$ & $\begin{array}{c}0.353^{* * *} \\
-\end{array}$ & -3.852 & \\
\hline$\alpha_{U N}$ & $0.017 * * *$ & -4.458 & \\
\hline R-squared & 0.54653 & & \\
\hline Adjusted R-squared & 0.50652 & & \\
\hline SE & 0.02141 & & \\
\hline \multicolumn{4}{|c|}{ Breusch-Godfrey Serial Correlation LM Test: } \\
\hline F-statistic & 0.15419 & Prob. $F(4,30)$ & 0.9596 \\
\hline Obs*R-squared & 0.76551 & Prob. Chi-Square(4) & 0.943 \\
\hline \multicolumn{4}{|c|}{ Sample 2006q1-2015q2 } \\
\hline
\end{tabular}

Combining equations ( 2 ) and ( 3 ), our business investment equation becomes:

$$
\begin{gathered}
\operatorname{logIB_{t}}=\operatorname{logIB_{t}-1}-0.315865+0.30696 \mathrm{CU}_{t}-0.01683 \mathrm{UNCERT}_{\mathrm{t}}-0.353091 \log \left(\frac{\mathrm{IB}}{\mathrm{Y}}\right)_{\mathrm{t}-1} \\
-0.05388 \log \mathrm{USER}_{\mathrm{t}-1}
\end{gathered}
$$

For consistency with the business investment equation, we have added UNCERT to our existing business capital stock simulation equation using the coefficient from the business investment equation multiplied by the average ratio of UK business investment to UK business capital between 1997 and 2015. The business capital equation becomes:

$$
\begin{aligned}
\operatorname{logKB_{t}} & =0.004364 \operatorname{logKB_{t}-1}+0.74 \log \Delta \mathrm{KB}_{\mathrm{t}-1}+0.042 \log \Delta \mathrm{Y}_{\mathrm{t}}+0.013 \log \Delta \mathrm{Y}_{\mathrm{t}-1} \\
& +0.0195\left(\log \left(\mathrm{KB}_{\mathrm{t}-1} / \mathrm{YCAP}_{\mathrm{t}+12}\right)+0.5 \log \mathrm{USER}_{\mathrm{t}-1}\right)-0.00072 \mathrm{UNCERT}_{\mathrm{t}}
\end{aligned}
$$

Following the methodology employed by Haddow et al. (2013), our measure of uncertainty is derived from extracting the first principal component from the following series:

1. FTSE option-implied volatility ${ }^{8}$

2. Sterling option-implied volatility ${ }^{9}$

3. $\mathrm{CBI}$ 'demand uncertainty limiting investment' score ${ }^{10}$

\footnotetext{
${ }^{8}$ Three-month option-implied volatility of the FTSE100 index.

${ }^{9}$ Three-month option-implied volatility of the sterling-euro and sterling-dollar export-weighted exchange rate.
} 
4. Economic policy uncertainty index ${ }^{11}$

Principal component analysis identifies a common trend from multiple series. The assumption underlying the method is that a common driver exists amongst these variables (see Stock and Watson, 2002). Each data series is stationary and each has been normalised prior to extracting principal components. This extracted series is our measure of uncertainty. Figure 21 shows the evolution of our measure of economic uncertainty over time.

Figure 21. Uncertainty index

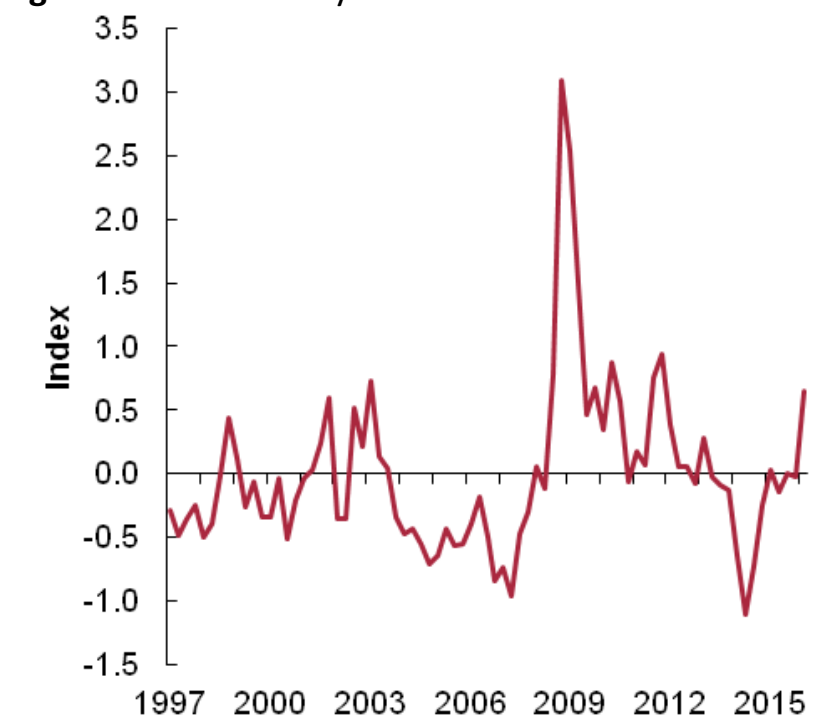

Source: NIESR calculations.

Notes: The NIESR Uncertainty Index series is a constructed series with mean zero and standard deviation one.

The advantage of using our composite measure over a single measure of uncertainty ${ }^{12}$ is that it captures different dimensions of uncertainty i.e. uncertainty as perceived by firms, financial markets, and investors. In addition, the composite measure is less noisy than any of its components.

10 'Uncertainty about demand' score from the question 'What factors are likely to limit your capital expenditure authorisations over the next twelve months' in the Confederation of British Industry's (CBI) Quarterly Industrial Trends and Service Sector surveys.

${ }^{11}$ Index based on newspaper articles regarding policy uncertainty. Source: http://www.policyuncertainty.com/index.html

${ }^{12}$ For instance, the OBR model uses the CBI 'demand uncertainty limiting investment' score as a predictor of business investment. 